\title{
Optimization of Activated Charcoal on in vitro Growth and Development of Potato (Solanum tuberosum L.)
}

\author{
Tanuja Buckseth $^{1 *}$, R.K. Singh ${ }^{1}$, Ashwani K. Sharma ${ }^{2}$, Sumita Sharma ${ }^{1}$, \\ Vaishali Moudgil $^{1}$ and Aastha Saraswati ${ }^{1}$ \\ ${ }^{1}$ Seed Technology Division, ICAR-Central Potato Research Institute, \\ Shimla-171001 (HP), India \\ ${ }^{2}$ Seed Technology Division, ICAR-Central Potato Research Station, \\ Kufri-171012 (HP), India \\ *Corresponding author
}

A B S T R A C T

Keywords

Activated charcoal, In vitro, Potato varieties

Article Info

Accepted:

25 September 2018

Available Online:

10 October 2018
Activated charcoal is often used in plant tissue culture to improve cell growth and development by absorbing the beneficial plant growth promoting substances from the media. Thus the main aim of this study was to evaluate the influence of different concentrations of activated charcoal on the recalcitrant varieties of potato. The MS media strength (full and half) did not influence the plant growth and development of potato varieties as both the strengths did equally well in combination with lower concentration of activated charcoal $(200 \mathrm{mg} / \mathrm{l})$. The use of activated charcoal could be done in a controlled manner (tested concentrations) in order to maintain the endophytes / microplant balance. However, studies in this line need further investigations for lowering the concentrations with a view to avoid the negative effects.

\section{Introduction}

Potato (Solanum tuberosum L.) is the fourth most important food crop of the world. It is an amenable crop which can be used in tissue culture techniques, ranging from in vitro propagation via shoot cultures for regeneration of whole plants from protoplasts (Buckseth et al., 2016). This whole plant can be regenerated from a range of cultured tissues like roots, leaves, tubers and stems or from single cells. In general terms, these all involve the growth of plant cells, tissues and organs in sterile conditions, supported by an appropriate culture medium (Harshal and Gautam, 2014). Murashige and Skoog medium (MS medium) is most widely used for the vegetative propagation of many plant species in vitro (Murashige and Skoog, 1962). Tissue culture based hi-tech seed potato production is spreading very fast in the country (Buckseth et al., 2017). Micropropagation at faster rate and free from cultural contamination is an integral component for the success of in vitro mass 
multiplication of potato (Buckseth et al., 2017). Activated charcoal is often used in plant tissue culture to improve cell growth and development. It stimulates nitrogen uptake by shoots and provides dark environment, which promotes in vitro rooting (Sharma et al., 2012). It is a porous and tasteless material which is distinguished from elementary carbon by removal of all non-carbon impurities and oxidation of carbon surface (Thomas, 2008). Several authors have reported its beneficial effect as a supplement on the media. Several authors reported that activated charcoal due to its beneficial effect has been used as a supplement on the media. It includes absorption of phenolic complex (Pan and Staden, 1998); root stimulator (George and Ravishankar, 1997); rhizome growth (Kim and Lee, 1992); development improvement (Choi and Chung, 1989); and absorption of toxic substances present in the media (Fridborg and Eriksson, 1978). Based on the performance on the standard Murashige and Skoog medium, the cultivar Kufri Jyoti has been classified as recalcitrant since the microplants during in vitro multiplication shows very slow growth, clumping of internodes, yellowing of basal leaves and premature senescence hence considered as recalcitrant variety (Venkataslam et al., 2015).

In view of the above, the main aim of the study was to analyze and evaluate the content of activated charcoal in half and full strength Murashige and Skoog media on different growth parameters of potato varieties Kufri Sindhuri and Kufri Jyoti.

\section{Materials and Methods}

The research was carried out at Central Potato Research Institute, Shimla to study the effect of activated charcoal in full and 1/2 strength MS media on different growth parameters of micro plant of Kufri Jyoti and Kufri Sindhuri. The standard culture medium (Murashige and
Skoog, 1962) and half strength MS media was supplemented with six different concentrations of activated charcoal i.e. $50 \mathrm{mgl}^{-1}, 100 \mathrm{mgl}^{-1}$, $200 \mathrm{mgl}^{-1}, 300 \mathrm{mgl}^{-1}, 400 \mathrm{mgl}^{-1}$ and $500 \mathrm{mgl}^{-1}$. Nodal segment culture in which the axillary and apical buds grow into new plants is predominantly used for initial shoot multiplication. The axillary/apical buds of these nodal segments grow into full plants within a period of about 3 weeks. These plants can be further sub-cultured on fresh medium. Excise nodal stem segments from the third and fourth nodes from the stem apex. Each nodal cutting should be 1-2 cm long, and the leaves should be detached. Such cuttings are used to initiate in vitro cultures (Buckseth et al., 2017).The explants used in the study were double-node cuttings derived from the middle portion of microplantlets. The explants (three double nodes per test tube) were cultured on the above said activated charcoal media along with control (MS medium without Activated charcoal). Culture tubes were incubated at $22 \pm 1^{\circ} \mathrm{C}$ under $16 \mathrm{hr}$ photoperiod (irradiance of $\left.60 \mu \mathrm{molm}^{-2} \mathrm{~s}^{-1}\right)$. After twenty-one days of culturing, observations were recorded on microplant height $(\mathrm{cm})$, number of leaves, nodes and roots, root length $(\mathrm{cm})$ of each microplant of a test tube. In case of number of roots only primary roots were counted and root length was recorded for the longest root of each plant. The experiment was conducted in a factorial completely randomized design. Each treatment comprised four replicates, each replicate consisting of four test tubes having three plantlets. The three-way analysis of variance was done using the software AGRES and means were separated according to the least significant differences at 0.05 level of probability and the graphs were prepared with the graph pad prism 5.0 software.

\section{Results and Discussion}

The experiment showed that the explants grown in activated charcoal full strength and 
half strength media produced desirable results as compared to the activated charcoal free media. However, the media strength (full and half) did not influence the plant growth and development of both the varieties as the strengths did equally well in combination with lower concentration of activated charcoal. Kufri Jyoti showed significant results $(28.5 \%$ increase) for microplant height and root length $\left(15.89 \%\right.$ increase) with treatment $\mathrm{T}_{2}$ $\left(\mathrm{MS}+100 \mathrm{mgl}^{-1}\right.$ activated charcoal) and $\mathrm{T}_{3}$ (MS+200 mgl ${ }^{-1}$ activated charcoal) when compared to the control (MS Media without activated charcoal) (Fig. 1A) Whereas, in Kufri Sindhuri, an increase of $50 \%$ in microplant height was found with $\mathrm{T}_{3}$ (MS+200 $\mathrm{mgl}^{-1}$ activated charcoal) and other growth parameters with different treatments $\left(T_{1}, T_{2}\right.$,
$\mathrm{T}_{3}, \mathrm{~T}_{4}, \mathrm{~T}_{5}$ and $\mathrm{T}_{6}$ ) of activated charcoal showed significant increase as compared to control (Fig. 1B). In case of number of leaves and nodes the results were on a higher side in Kufri Jyoti with treatment $\mathrm{T}_{5}\left(\mathrm{MS}+400 \mathrm{mgl}^{-1}\right.$ activated charcoal) when compared to the control (Fig. 1A). However, Bansal and Gokhale (2012) reported that in Oroxylum indicum the shoots formed in the presence of the activated charcoal were rather weak with small leaves. They observed that only low and moderate concentrations of activated charcoal were impelling, while high concentrations failed to induce rooting. It is possible that the addition of high concentrations of AC may induce nutrient deficiencies in culture media. Such a deficiency will affect explant growth and rooting (Pan and Staden, 1998).

Fig.1 Effect of activated charcoal full strength MS Media on in vitro growth of (A) Kufri Jyoti; and (B) Kufri Sindhuri; C, control; $\mathrm{T}_{1},\left(\mathrm{MS}+50 \mathrm{mgl}^{-1} \mathrm{AC}\right) ; \mathrm{T}_{2},\left(\mathrm{MS}+100 \mathrm{mgl}^{-1} \mathrm{AC}\right) ; \mathrm{T}_{3}$, $\left(\mathrm{MS}+200 \mathrm{mgl}^{-1} \mathrm{AC}\right) ; \mathrm{T}_{4},\left(\mathrm{MS}+300 \mathrm{mgl}^{-1} \mathrm{AC}\right) ; \mathrm{T}_{5},\left(\mathrm{MS}+400 \mathrm{mgl}^{-1} \mathrm{AC}\right) ; \mathrm{T}_{6},\left(\mathrm{MS}+500 \mathrm{mgl}^{-1} \mathrm{AC}\right)$

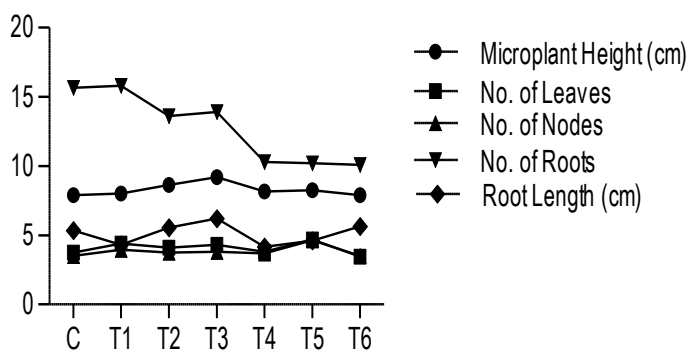

A. Kufri Jyoti

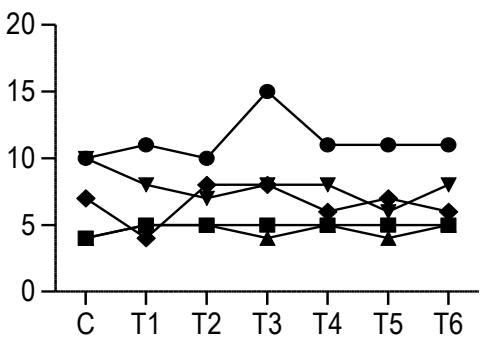

B. Kufri Sindhuri

Fig.2 Effect of activated charcoal half strength MS Media on in vitro growth of (A) Kufri Jyoti; and (B) Kufri Sindhuri; C, control; $\mathrm{T}_{1},\left(1 / 2 \mathrm{MS}+50 \mathrm{mgl}^{-1} \mathrm{AC}\right) ; \mathrm{T}_{2},\left(1 / 2 \mathrm{MS}+100 \mathrm{mgl}^{-1} \mathrm{AC}\right) ; \mathrm{T}_{3}$, $\left(1 / 2 \mathrm{MS}+200 \mathrm{mgl}^{-1} \mathrm{AC}\right) ; \mathrm{T}_{4},\left(1 / 2 \mathrm{MS}+300 \mathrm{mgl}^{-1} \mathrm{AC}\right) ; \mathrm{T}_{5}:\left(1 / 2 \mathrm{MS}+400 \mathrm{mgl}^{-1} \mathrm{AC}\right) ; \mathrm{T}_{6}$ :

$$
\left(1 / 2 \mathrm{MS}+50 \mathrm{mgl}^{-1} \mathrm{AC}\right)
$$

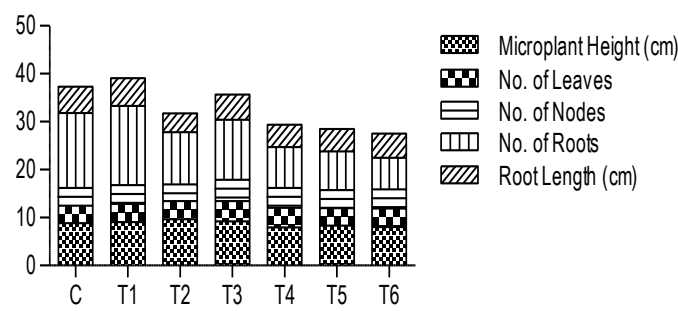

A. Kufri Jyoti

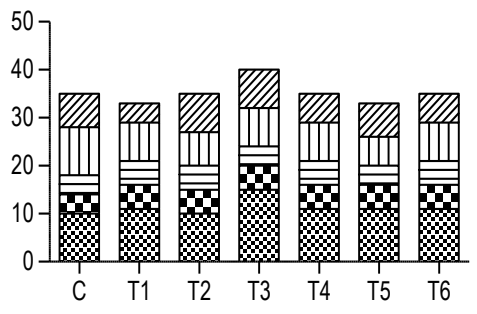

B. Kufri Sindhuri 
Roots developed in in-vitro regenerated shoots on this rooting media were long, thin, unbranched and too weak to be transferred for hardening process. For the number of roots in Kufri Jyoti as the concentration of activated charcoal increased there was a decrease in root formation. However, treatment $\mathrm{T}_{1}$ $\left(\mathrm{MS}+50 \mathrm{mgl}^{-1}\right.$ activated charcoal) produced better results but on comparing with control no significant difference was observed. Treatment $\mathrm{T}_{2} \quad\left(\mathrm{MS}+100 \mathrm{mgl}^{-1} \quad\right.$ activated charcoal) and $\mathrm{T}_{3}\left(\mathrm{MS}+200 \mathrm{mgl}^{-1}\right.$ activated charcoal) resulted in higher rate of root length in Kufri Sindhuri whereas, for the number of roots the results were more desirable in control when compared to the other treatments which were in agreement with the findings of Nisyawati and Kusuma (2013) and Das and Srivastav (2015) where the explants of banana cultivar Barangan (Musa acuminata L.) produced higher number of shoots on activated charcoal-free media than those on media with addition of different concentrations of activated charcoal. Same results of both the varieties in half strength media were observed wherein the microplant height was $12.8 \%$ more with treatment $\mathrm{T}_{2}$ $\left(1 / 2 \mathrm{MS}+100 \mathrm{mgl}^{-1}\right.$ activated charcoal) in comparison to the other treatments as well as control (Fig. 2A, B). According to Moraes et al., (2005) and Agata et al., (2010), media supplemented with activated charcoal improved the in vitro propagation of Brazilian native orchids and Zygostates grandiflora. Activated charcoal also plays an important role in orchid seed germination (Kull and Arditti, 2002; Moraes et al., 2005). In case of number of roots and root length, the results were significantly higher with treatment $\mathrm{T}_{1}$ $\left(1 / 2 \mathrm{MS}+50 \mathrm{mgl}^{-1}\right.$ activated charcoal). However, as the concentration of activated charcoal increased there was a decrease in the number of roots. For number of leaves and number of nodes no significant difference was found between different treatments and the control. It has been observed that activated charcoal stimulate growth and differentiation during culture regeneration (Nayanakantha et al., 2010) whereas its addition to the regeneration media may have adverse effects on growth and development, as activated charcoal is able to absorb high concentration of growth regulators (Fernando et al., 2010). The non-selective adsorption of growth regulators may result in inhibitory effects of growth in vitro (Thomas, 2008). Activated charcoal has a significant effect on the potato microtuber induction. The positive effect of Activated charcoal on microtuberization might be due to adsorption of ethylene (a strong inhibitor for tuberization) and reduction of light in root medium. Reduction of light at the base of a shoot can provide a conducive environment to the accumulation of photosensitive auxin or co-factors (Hassan et al., 2011). Therefore, it can increase tuber yield and greatly shorten the time of microtuber induction (Xu, 2003 and Liu, 2001). Thomas (2008) reported that the concentration of activated charcoal differed widely in plant tissue culture from a range of $0.002 \mathrm{gl}^{-1}$ to $150 \mathrm{gl}^{-1}$. The concentration may be related to different plant species, medium, explants, purpose etc.

Thus, it could be concluded that the genotype is solely responsible to confer the microplants sensitivity as well as its tolerance limit against different supplements in MS media. It is therefore considered of utmost importance that the use of these supplements (Activated charcoal) could be done in a controlled manner (concentrations) in order to maintain the endophytes / microplant balance.

\section{Acknowledgements}

The authors are grateful to the Indian Council of Agricultural Research, New Delhi, India for providing financial supports and necessary facilities to carry out the research work and Dr. E.P. Venkataslam, Sr. Scientist and 
Incharge, ICAR-CPRS, Ooty for providing the baseline data to conduct the research.

\section{References}

Agata, Pacek-Bieniek, Dyduch-Sieminska, Magdalena and Michal Rudas. 2010. Influence of activated charcoal on seed germination and seedling development by the asymbiotic method in Zygostates grandiflora (Lindl.) Mansf. (Orchidaceae). Folia Horticulturae Ann., 22/2, 45-50.

Bansal, Y.K. and M. Gokhale. 2012. Effect of Additives on Micropropagation of an Endangered Medicinal Tree Oroxylum indicumL. Vent. In: Recent Advances in Plant in vitro Culture (Eds.: Annarita, Leva and Laura M.R. Rinaldi).

Bhoite, Harshal A., and S. Palshikar Gautam. 2014. Plant Tissue Culture: A Review. World J. Pharm. Sci., 2(6), 565-572.

Buckseth, T., A.K. Sharma, K.K. Pandey, B.P. Singh and R. Muthuraj. 2016. Methods of Pre-basic seed potato production with special reference to aeroponics - A Review. Scientia Horti., 204, 79-87.

Buckseth, T., R.K. Singh, S. Sharma, Ashwani K. Sharma, V. Moudgil and A. Saraswati. 2017. Antibiotics Efficacy on In Vitro Growth Parameters of Important Potato Cultivars. Int. J. Curr. Microbiol. App. Sci, 6(11), 956-963.

Buckseth, T., R.K. Singh, S. Sharma, Ashwani K. Sharma, V. Moudgil and A.Saraswati. 2017. Effect of Streptomycin and Gentamycin on in vitro Growth and Cultural Contaminants of Potato Cultivars. Int. J. Curr. Microbiol. App. Sci, 6(12), 4038-4043.

Choi, S.O. and J.D. Chung. 1989. Effects of media on multiplication of rhizomes and growth of seedlings through asymbiotic seed germination of oriental
Cymbidium. J. Kor. Soci. Horti. Sci., 30, 294-302.

Das, Priyanka and A. K. Srivastav. 2015. To Study the Effect of activated charcoal, ascorbic acid and light duration on in vitro micropropagation of Aloe vera $\mathrm{L}$. IJIRSET., 4(5), 2347- 2353.

Fernando, S. C., E.S. Santha and D.J.A. Hewarathna. 2010. Activated coconut shell charcoal as a component of tissue culture media of Cocus nucifera L. J. Nat. Sci. Found. Sri Lanka, 38(3), 181185.

Fridborg, G. and T. Eriksson. 1978. Effects of activated charcoal on growth and morphogenesis in cells cultures. Uppsala, Sweden. Physiol. Plant., 34, 306-308.

George, P.S. and G.A. Ravishankar: 1997. In vitro multiplication of Vanilla planifolia using axillary bud explants. Plant Cell Rep., 16, 490-494.

Hassan, M. L., Behrooz, E. and Esmaie, C. 2011. Hinokitiol and activated charcoal influence the microtuberization and growth of potato (Solanum tuberasum cv. Agria) plantlets in vitro. Australian J. Crop Sci. 5(11), 1481-1485.

Kim, J.Y. and J.S. Lee. 1992. Effect of cultural conditions on rhizome growth and organogenesis of Cimbidium lancifolium native Korea in vitro. $J$. Kor. Soci. Horti. Sci., 33, 471-476.

Kull, T. and J. Arditti: Orchid Biology: Reviews and Perspectives, VIII. Kluwer/Springer, (2002)

Liu, R. X. 2001. Effect of Activated Charcoal and Inorganic Nutrition on the Induction of the Test-Tube Potato," Plant Physio. J., 37, 295-298.

Moraes, L.M., R.T. Faria and F.L. Cuquel. 2005. Activated charcoal for in vitro propagation of Brazilian orchids. Acta Hort., 683, 383-390.

Murashige, T. and F. Skoog. 1962. A revised medium for rapid growth and bio assays 
with tobacco tissue cultures. Phisiol. Plant., 15, 473-497.

Nayanakantha, N.M.C., B.R. Singh and A. Kumar. 2010. Improved culture medium for micropropagation of Aloe vera $\mathrm{L}$. Trop. Agri. Res. Ex., 13(4), 87-93.

Nisyawati and K. Kariyana. 2013. Effect of ascorbic acid, activated charcoal and light duration on shoot regeneration of banana cultivar barangan (Musa acuminata L.) in vitro culture. IJRRAS, 15 (1), 02.

Pan, M.J. and Van Staden, J. 1998. The use of charcoal in in-vitro culture-a review. Plant Growth Regul., 26: 155-63.

Sharma, P.K., R. Trivedi and Purohit, S. 2012. Activated charcoal improves rooting in in-vitro derived Acacia leucophloea shoots. Inter. J. Plant Dev. Biol., 6(1), 47-50.

Thomas, Dennis T. 2008. The role of activated charcoal in plant tissue culture. Biotechnol. Adva., 26, 618631.

Venkatasalam, E.P., J. Latawa, S.K. Chakrabarti, K.K. Pandey, R. Sood, V. Thakur, A.K. Sharma and B.P. Singh. 2015. Standardization of medium for micropropagation of recalcitrant potato (Solanum tuberosum L.) cultivar Kufri Jyoti. Potato J., 42(2), 116-123.

Xu, C. Z., X. J. Zhang and A. J. Liu. 2003. Effect of Activated Charcoal on explant growth and tuberization in Potato, Review of China. Agri. Sci. Tech., 5,106-107.

\section{How to cite this article:}

Tanuja Buckseth, R.K. Singh, Ashwani K. Sharma, Sumita Sharma, Vaishali Moudgil and Aastha Saraswati. 2018. Optimization of Activated Charcoal on in vitro Growth and Development of Potato (Solanum tuberosum L.). Int.J.Curr.Microbiol.App.Sci. 7(10): 3543-3548. doi: https://doi.org/10.20546/ijcmas.2018.710.410 